\title{
Gross Alpha/Beta Radioactivity Determination in Water Samples from Some Mining Sites, Wurno LGA, Sokoto state, Nigeria
}

\author{
Y.M. Ahijjo \\ Department of Physics, Usmanu Danfodiyo University, Sokoto, Nigeria. Email: yahijjomusa@gmail.com
}

DOI: http://doi.org/10.46382/MJBAS.2021.5302

Copyright: (C2021 Y.M. Ahijjo. This is an open access article distributed under the terms of the Creative Commons Attribution License, which permits unrestricted use, distribution, and reproduction in any medium, provided the original author and source are credited.

Radioactivity exposure level from some mining sites in Wurno LGA, Sokoto have been determined in this paper. The inhabitant's exposure rates were found through in-situ radiation measurement and liquid scintillation counting of water samples. An invented equation for sampling was used to spot out points. Measurement was done with Digilert-50 at Gonadal height from 15 points. Three closed points were averaged to 5 points between; Kandam, Gyalgyal, Burmawan Masaka, Dinbiso and Giyawa mining sites respectively. Water samples were collected for Hidex 300 liquid scintillation counting of gross alpha and beta radioactivity. The mean in-situ radiation results were $0.206,0.317,0.108,0.335$ and $0.230 \mu S v$ for the sample points. Annual effective dose and cancer risk were found in range of $0.32542-0.411125 u S v h r^{-1}$ and $5.01 \times 10^{-1}-1.56 \times 10^{1}$ respectively These values were found significantly higher than the WHO and ICRP levels. Dangers from ransacking the major rocks that harbors these nuclides may be more prominent. These trends should be curtailed by authorities to avert future menace of environmental and health maladies.

Keywords: Radioactivity, Hidex, Mining sites, Domestic water, Liquid scintillation counters.

\section{Introduction}

Numerous studies are ongoing for gross alpha and beta radioactivity in domestic water samples worldwide [1]. The commitment is part of a demand to ensure water safety consumption. Consumption of contaminated water is a growing danger, especially in Africa. This is also anticipated in Sokoto (Iullemeden) basin, Nigeria [2]. Findings are on increase to report radionuclides presence in domestic water in mining communities [1]. This article is an excerpt from a large scale finding from health and environmental concern of radiological impacts of mining sites in the Sokoto basin [3]. The basin is famous for mining of Gold, Diamond, Limestone, Kaolin, Gypsum, Phosphate, Tantalite, Iron-ore with promising potentials for Hydrocarbons [4].

Efforts on gross alpha/beta radioactivity in water are also increasing [5]. World health organization is firming up effort to ascertaining water qualities in rural community [6]. Environmentally, three forms of radionuclides often pose dangers to human health viz: cosmogonic radionuclides $\left({ }^{3} \mathrm{H},{ }^{7} \mathrm{Be},{ }^{10} \mathrm{~B},{ }^{14} \mathrm{C},{ }^{36} \mathrm{Cl}\right.$ and ${ }^{32} \mathrm{Si},{ }^{22} \mathrm{Na},{ }^{38} \mathrm{SS}$ and $\left.{ }^{33} \mathrm{P}\right)$, primordial Radionuclides $\left({ }^{40} \mathrm{~K},{ }^{87} \mathrm{Rb},{ }^{50} \mathrm{~V},{ }^{144} \mathrm{Nd},{ }^{238} \mathrm{U},{ }^{235} \mathrm{U},{ }^{232} \mathrm{Th}\right)$ and anthropogenic radionuclides $\left({ }^{137} \mathrm{Cs},{ }^{90} \mathrm{Sr}\right.$, ${ }^{89} \mathrm{Sr},{ }^{131} \mathrm{I},{ }^{99} \mathrm{Tc},{ }^{240} \mathrm{Pu},{ }^{241} \mathrm{Am},{ }^{65} \mathrm{Zn},{ }^{54} \mathrm{Mn},{ }^{55} \mathrm{Fe}$ ) [7]. These radionuclides have been implicated for contaminating food and ultimately water [8]. Over $80 \%$ of human exposure comes from these primordial origins. As such, resources have been streamlined into ascertaining the level of their contamination [3]. Hence, effort is required to unveil major alpha/beta emitting radionuclides in water samples [9].

The dangers are often high in biological systems through ingestion, inhalation and percolation. Life supporting molecules (DNA of cells) are destroyed through linear energy transfer of the ionizing radiation [9]. Lethal attack arising from reactive radicals may lead to either partial or utter damage of DNA. Bichi 2006 [10] asserts that unrepaired or ill-repaired occurrence may annihilate cells or lead to abnormal cell growth. Scanty data on gross 
alpha/beta radioactivity from mining and processing of minerals could signal grave radiological impacts in both urban and rural dwellings [11]. Most mining communities in Sokoto (Iullemeden) basin are populated [4]. This is a vacuum that this research intends to address at completion. Hidex 300 SL liquid scintillation counting was found to enables triple-to-double coincidence ratio counting (TDCR) of water samples without dependency on external standard source [12].

\section{Materials and Methods}

In-situ background ionizing radiation (BIR) was conducted with a Digilert-50 hand held radiation measuring instrument through the use of an invented equation (1) below [3].

$\Sigma_{\sigma}=\frac{S_{\rho}}{\sigma}\left(N_{k}\right)$

Where, $\Sigma_{\sigma}$ is the sum of the questionnaires distributed, $S_{\rho}$ is the number of sample points, $\sigma$ is the sum of the sample points and $N_{k}$ is the sum of all the Questionnaires. The validity of this model equation (1), was ensured for its innovation. A stratified random sampling by proportion was used to collect the samples. Mutually exclusive and collectively exhaustiveness logics according to Singh and Audu, [13] were noted to improve the representativeness of the sample and to reducing sampling error and biasness. This paper is a concise aspect of a completed $\mathrm{PhD}$ work where equation (1) was innovated and used for collecting questionnaires (survey), soil, water and vegetation samples from Kebbi, Sokoto and Zamfara state. Here, only one LGA (Wurno) from Sokoto state is reported [4].

\section{The Study Area}

Sampling was conducted from 15 mining sites and averaged to 5 sample points in Wurno LGA, Sokoto state. This includes; Kandam, Gyalgyal, Burmawan Masaka, Dinbisu and Giyawa. Figure 1 presents the Map of Wurno LGA with indications of the sample points. Wurno is geographically located on Latitude 13 17' $03^{\prime \prime}$ and Longitude $525^{\prime}$ 39". It is an enclave of Iullemeden basin which covers an area of about 500,000 $\mathrm{km}^{2}$ across some West African countries including Nigeria [4]. $60,000 \mathrm{~km}^{2}$ equivalent to $10.7 \%$ of total Iullemeden basin in West Africa occurred in Nigeria with dynamic and important geological features mostly sedimentary phosphates [14]. Mining in Iullemeden basin is embraced for its positive contributions in form of increased income, local employment opportunities, provision and maintenance of domestic facilities. Hence, the notion of gross alpha and beta radioactivity are not familiar with the need and importance of mining for its varied and relative benefits from the populace.

\subsection{Sample Collection}

A total of fifteen water samples were collected on the basis of stratified random sampling by proportion. The sample points were unbiasedly ascertained with the use of equation (1) as earlier discussed. Base on the mutually exclusive and collectively exhaustive features, it established the geological homogeneity for parts of the basin. Three samples from closely adjacent points were homogenized to further mimic the cost of procurements and to enhance the empirical underlying principle of equation (1). 


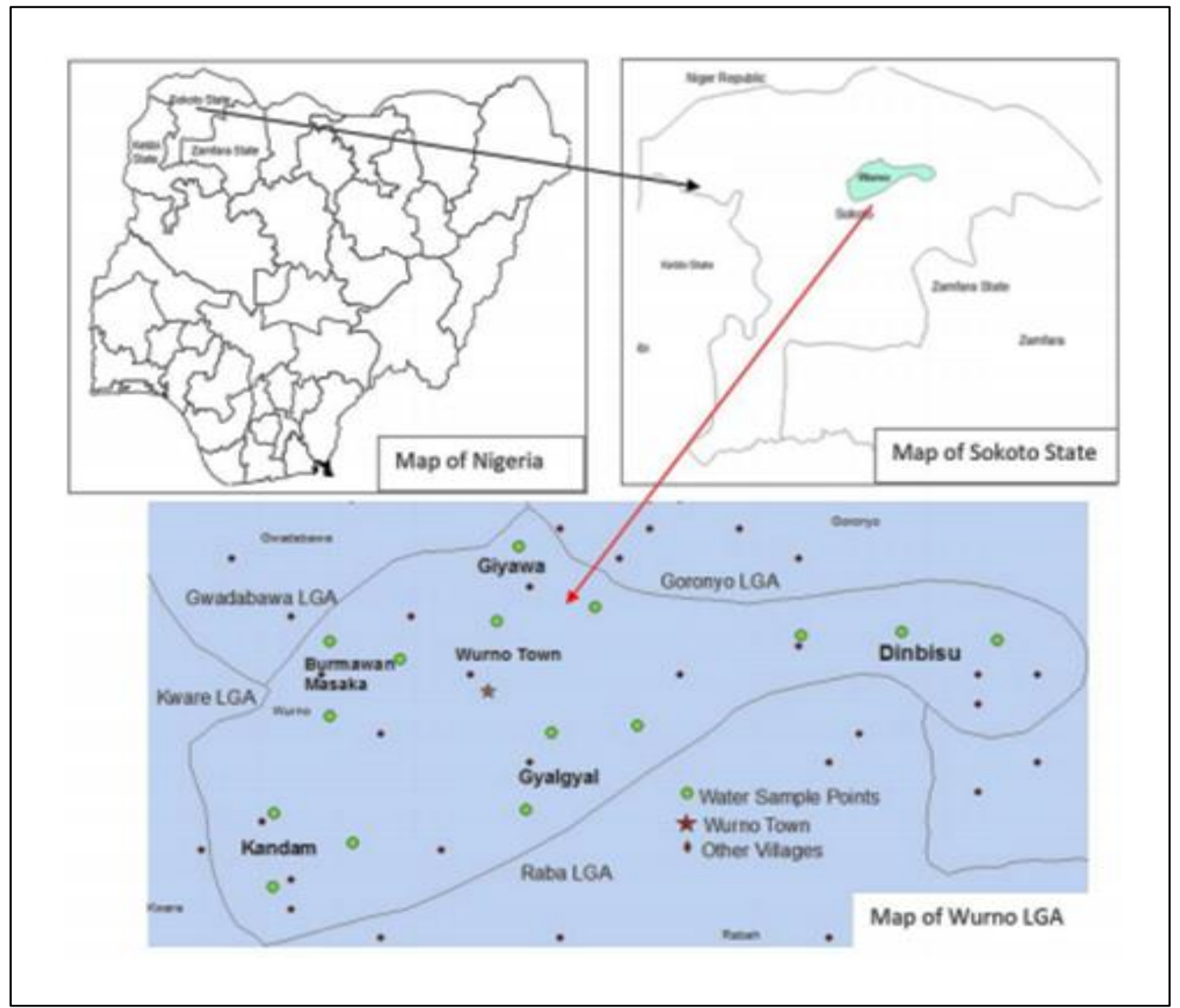

Fig.1. Illustrations of Maps showing the study area and the sample points

It was also found cost effective in addressing logistic burden from Nigeria to Pakistan (CASP, GCU, Lahore) for analysis. Table 1 below presents a glimpse of the distribution of the samples after homogenization [3].

\section{A. In-situ BIR Measurement}

A hand-held radiation survey meter Digilert 50 with built in Halogen-quenched Geiger-Mueller tube and an effective diameter of 1.75" (45 mm), Mica window density of $1.5-2.0 \mathrm{mg} / \mathrm{cm} 2$ was employed for the in-situ measurement. The instrument has a gamma sensitivity of approximately $7.5 \mathrm{CPS} / \mathrm{mR} / \mathrm{hr}$ referenced to ${ }^{60} \mathrm{Co}$ and has smallest detectable level for ${ }^{125} \mathrm{I}$ at $0.02 \mu \mathrm{Ci}$ at each contact. The accuracy over the entire operating range was \pm $15 \%$. Also, alpha, beta, gamma and $\mathrm{X}$-rays detection is within the temperature range of $-10^{\circ}$ to $+50{ }^{\circ} \mathrm{C}$ which is equivalent to $14^{\circ}$ to $122^{\circ} \mathrm{F}$. Reading was taken by 15 counts to increase accuracy and mimic any error. The average values of the measured BIR were calculated from the recorded values which were subsequently converted to a unified value base on the stratifications by averaging to five sample points.

The measured BIR values were used to calculate for the absorbed doses using occupancy factors of $20 \%$. The effective doses were evaluated based on the equivalent doses obtained. This was considered for the fact that BIR emanating from radionuclides decay and cosmic radiation influence may varies slightly in time. Annual effective dose was determined by equation 2 : 
$\mathrm{E}_{\text {dose }}=D_{m} A b s+t_{t} k \mathfrak{J}_{f_{c}} \times C_{\text {onv }_{f}}$

Where, $\mathrm{E}_{\text {dose }}$ is the annual effective dose received by the individual exposure in the respective sample points. $D_{m} A b s$ is the mean absorbed dose rates in the air at the sample points, $t_{t}{ }_{k}$ is the time spent converter from hour to year $(8760 \mathrm{~h}), \mathfrak{J}_{f_{c}}$ is the occupancy factor (it is a function of time spent at sample points $\left.(0.2)\right), C_{o n v_{f}}$ is conversion factor from $D_{m} A b s$ to $\mathrm{E}_{\text {dose }}$ (recommended by UNSCEAR) [15]. Also, the life time cancer risk to any individual was determined from equation 3 [16].

$C_{\text {life }}=D_{m} A b s=A l_{e x} \times R_{f}$

Using the absorbed dose rate $\left(D_{m} A b s\right)$ with the average life expectancy $\left(A l_{e x}\right)$ of 65 for average Nigerians and a conversion risk factor of $5.82 \times 10^{-2}$

Table 1. Water sample collection and other measurement performed during sampling

\begin{tabular}{|c|c|c|c|c|}
\hline $\begin{array}{ll}\mathrm{S} / \text { no } & \mathrm{S} / \text { Code }\end{array}$ & Location & Elevation & Mineral & Town/Village \\
\hline 1. WUR $\mathrm{WOKI}_{\mathrm{SO}}$ & $\mathrm{N} 13^{0} 08.606^{\prime} \mathrm{E} 005^{0} 20.712^{\prime}$ & 813 meters & Gypsum & Kandam \\
\hline 2. $\mathrm{WUR}_{\mathrm{SOK} 2}$ & $\mathrm{~N} 13^{\circ} 06.790^{\prime} \mathrm{E} 005^{\circ} 21.871^{\prime}$ & 820 meters & Limestone & Gyalggal \\
\hline 3. WUR SOK3 $_{5}$ & $\mathrm{~N} 13^{0} 06.728^{\prime} \mathrm{E}^{2} 05^{\circ} 21.851^{\prime}$ & 838 meters & Phosphate & B/Masaka \\
\hline 4. WUR ${ }_{S O K 4}$ & $\mathrm{~N} 13^{0} 19.840^{\prime} \mathrm{E}^{\prime} 05^{0} 29.445^{\prime}$ & 986 meters & Gypsum & Dinbisu \\
\hline 5. WUR $\mathrm{WOK}_{5}$ & $\mathrm{~N} 13^{0} 26.768^{\prime} \mathrm{E} 005^{0} 41.250^{\prime}$ & 1125 meters & Gypsum & Giyawa \\
\hline
\end{tabular}

\section{Experimental Procedures}

Hidex 300 SL, liquid scintillation counting of gross alpha and beta activity concentrations was used in this study. It was operated on a PC Windows based Mikrowin SL software. The counting efficiency is 70 to $100 \%$ of ${ }^{3} \mathrm{H} /{ }^{14} \mathrm{C}$. Its designs include detection of radioactivity from alpha-emitters, actinides: Th, U, Pu, Am, Cm, alpha and beta-emitters from the $\mathrm{U}$ and Th decay series: ${ }^{228} \mathrm{Ra},{ }^{226} \mathrm{Ra},{ }^{210} \mathrm{~Pb},{ }^{210} \mathrm{Po}$. It has a capacity of loading 40 glass vials in its sample wells for counting at a time [3]. The experimental procedure for gross alpha/beta determination in water sample is; organic matter deactivation, filtration, instrument calibration, sample measurement and experimental observations.

\section{(1) Organic Matter Deactivation}

Sample preparation was initiated by weighing of empty glass vial and thereby recording its weight. The vials were filled up to $1 / 3(22 \mathrm{ml})$ of their total volume. The weight of the vial plus the weight of the sample were then reweighed and noted. They were then passed under a UV light with a peak emission of wavelengths between 225 $\mathrm{nm}$ to $235 \mathrm{~nm}$ for about $30 \times 10^{-9} \mathrm{sec}$. in order to deactivate the inherent organic matter retention in the samples. This was particularly performed so as to allow the organic matter to remain undecomposed and without being dissolved in order to achieve higher degrees of immiscibility with the water sample. Each of the glass vials were then removed from the set up in order to allow the content settles at room temperature for an hour. The 
weights of all the empty glass vials were then subtracted from the weight of the glasses vial plus the sample. And the weights were therefor established in order to determine any reduction of the content in the glass vials. This procedure was repeated for all the samples brought into the laboratory for measurement as earlier outlined in the synopsis of the study.

\section{(2) Filtrations}

The samples were allowed to settle under normal room temperature for an hour. The sample in the glass vials which were in the state of mixture were then poured through a filter funnel into a dark flask to enable the separation of particles in solid or near solid state from the liquid sample. $1 \mathrm{M}$ of $\mathrm{HNO}_{3}$ was prepared with a deionized water to wash the empty glass vials. They were allowed to settle in the flask for an additional 600s until no organic solids were visible in the samples.

\section{(3) Calibration}

A self-normalization and calibration standards containing ${ }^{14} \mathrm{C},{ }^{3} \mathrm{H}$ and ${ }^{226} \mathrm{Ra}$ source of $1 B q L^{-1}$ were ensured for calibration. The source was added to the sample in LSC vials and mixed with the sample until the final volume of the sample was $20 \mathrm{ml}$. The counting efficiency and the optimal condition for the alpha/beta separation was obtained by observing the 30 -day equilibration period storage in a dark cupboard. A dark effect was attained within the first $2-3$ quarters of the storage duration in the dark cupboard. Chemiluminescence influence was curtailed for the samples concentration in the LSC cocktail which could potentially result to emission of light due to chemical reaction between the water sample and the cocktail leading to false pulse reading (DPM). The energy range (ROI) between $0-600$ was set for the channel number between $0-20$ count per channel for alpha and beta counting efficiencies. The background count rate and the counting efficiency were used to determine the Minimum Detectable Activity (MDA).

\section{(4) Sample Measurement}

All the glass vials were gauged at $20 \mathrm{ml}$ in volume of the sample (water) before the counting procedure. The samples were place inside the Hidex 300 SL rack for LSC measurement. The samples were counted in quadruplicate for 6000 secs. The scintillate (light) emitted when responding to the irradiation was recorded as the amount of radioactivity in the samples. In each of the sample count, the first rounds of the measurement were discarded in order to reduce errors that may arise from influence of rigorous shacking (Kinetic influence) of handling the samples prior measurement. The samples were measured in the LSC operation of moving the samples racks from the staging tray into the detection chamber. Since the counting was performed in quadruplicate, the average count of the samples was obtained from the three measurements.

\section{(5) Observation}

The observations of alpha and beta emitting radionuclides are known to produce different shapes at the PMT's anode and were separated by pulse discriminator. They were separated based on their distinguishable features from one another. This was handled in an automatic electronic pulse discriminator in the Hidex 300 SL. There were two 
major pulse components observed: These pulses were noticed to occur at different proportions. The alpha pulses were found longer than the beta pulses. The liquid scintillation and the nuclides were combined in the cocktail initially in order to optimize the counting efficiency of alpha and beta radioactivity. This was in a bid to allow incident radiation deposited in the solvent molecules which thereby transfers the energy to the flour (solute) molecules. The kinetic theory observations in this procedure were that, part of the kinetic energy of the ionizing radiation (gross alpha/beta) were transferred to the cocktail and were converted to signals which were detected by electronic component of the system. Photons were produced from the fast exponential decay of excited singlet states. This was observed to take a minimum of $50 \mathrm{nsec}$. and maximum of $70 \mathrm{nsec}$.

The outputs resulted to a longer lifetime that produced the delayed component of the pulse. For alpha particle, it was observed that higher ionization caused a greater proportion of excited molecules to be in triplet state and hence, alpha pulse took longer duration of time. This longer duration of alpha pulses was the basis of alpha/beta separation by pulse shape discrimination. The pulse shape produced at the PMT anode of the Hidex 300 SL was averaged out using a storage oscilloscope that was set in order to take the average of the incident signal to produce an average pulse shape. But the photons were not of paramount interest in this experiment, therefore, a pulse shape discrimination electronic was used to effectively ensure a gamma-rays background rejection and isolation of fission events. This was found to enable the enhancement and optimization of Figure of Merit (FOM), which is a qualitative representation of the statistical quality of the data (results) to be obtained from LSC analysis. The background readings were observed to be $0.03 \pm 0.01$ and $0.20 \pm 0.01 \mathrm{cpm}$ for alpha and beta activity concentrations. As long as the chamber has the capacity of handling the sizes in the designated instrument, the gross alpha and beta radioactivity could be manually established by calculations using equations 3 and 4 according to Nisti et al. [17].

$\alpha(p C i / L)=\frac{A \times 1000}{2.22 \times C \times V}$

Where: $\mathrm{A}$ is the net alpha count rate (gross alpha count rate minus the background count rate) at, the alpha voltage plateau of $1000, \mathrm{C}$ is the alpha efficiency factor from graph of efficiency (cpm/dpm), $\mathrm{V}$ is the volume of sample aliquot in ml., 2.22 is the conversion factor from Dpm/pCi.

$$
\beta(p C i / L)=\frac{B \times 1000}{2.22 \times D \times V}
$$

Where: $\mathrm{B}$ is the net beta count rate (gross count rate minus the background count rate at the beta voltage plateau of 1000), $\mathrm{D}$ is the beta efficiency factor from the graph of efficiency (cpm/dpm), $\mathrm{V}$ is the volume of sample aliquot in ml., 2.22 is the conversion factor from Dpm/pCi but, $1 \mathrm{Ci}=3.7 \times 10^{10} \mathrm{~Bq}$ For conversion from Curie to Becquerel.

\section{Results}

Table 2 presents the averages of measured absorbed dose rates in air and other calculated parameters for the evaluation of individual exposure levels in Wurno LGA. Also, figures $2 \mathrm{a} \& \mathrm{~b}$ illustrates the respective trends of the measured and calculated parameters for the exposure to radioactivity by individual inhabitants. The activity concentrations of primordial radionuclides present at any given place are believed to be responsible, hence the 
results offer a glimpse of the levels of gross alpha/beta radioactivity. The average amount of BIR dose measured from Dinbiso appeared highest while Burmawan Masaka is the lowest on the table. This may be due to variations in the components that may account for the BIR at any given place like the concentration of primordial radionuclide and contribution from cosmic rays. These values are significantly above $0.1 \mu \mathrm{Svhr} r^{-1}$ recommended by [16], that was set as the threshold value. The respective annual effective dose received by the inhabitants of these localities also ranged from $0.132542 \mu \mathrm{Svhr}^{-1}$ to 0.411125 . This is to say that, the level of exposure at the sites in Dinbiso is significantly high compare to the remaining values of calculated annual effective dose in the air [18].

Table 2. Presentation of results from Calculations

\begin{tabular}{|lllll|}
\hline S/n & $\begin{array}{l}\text { Sample } \\
\text { Points }\end{array}$ & $\begin{array}{l}\text { Measured BIR } \\
(\mu S v)\end{array}$ & $\begin{array}{l}\text { Annual Effective } \\
\text { Dose }\left(\mu S v h r^{-1}\right)\end{array}$ & Cancer Risk \\
\hline 1. & Kandam & 0.206 & 0.252811 & $9.56 \times 10^{-1}$ \\
2. & Gyalgyal & 0.317 & 0.389035 & $1.47 \times 10^{1}$ \\
3. & Burmawan Masaka & 0.108 & 0.132542 & $5.01 \times 10^{-1}$ \\
4. & Dinbiso & 0.335 & 0.411125 & $1.56 \times 10^{1}$ \\
5. & Giyawa & 0.23 & 0.282265 & $1.07 \times 10^{1}$ \\
\hline
\end{tabular}

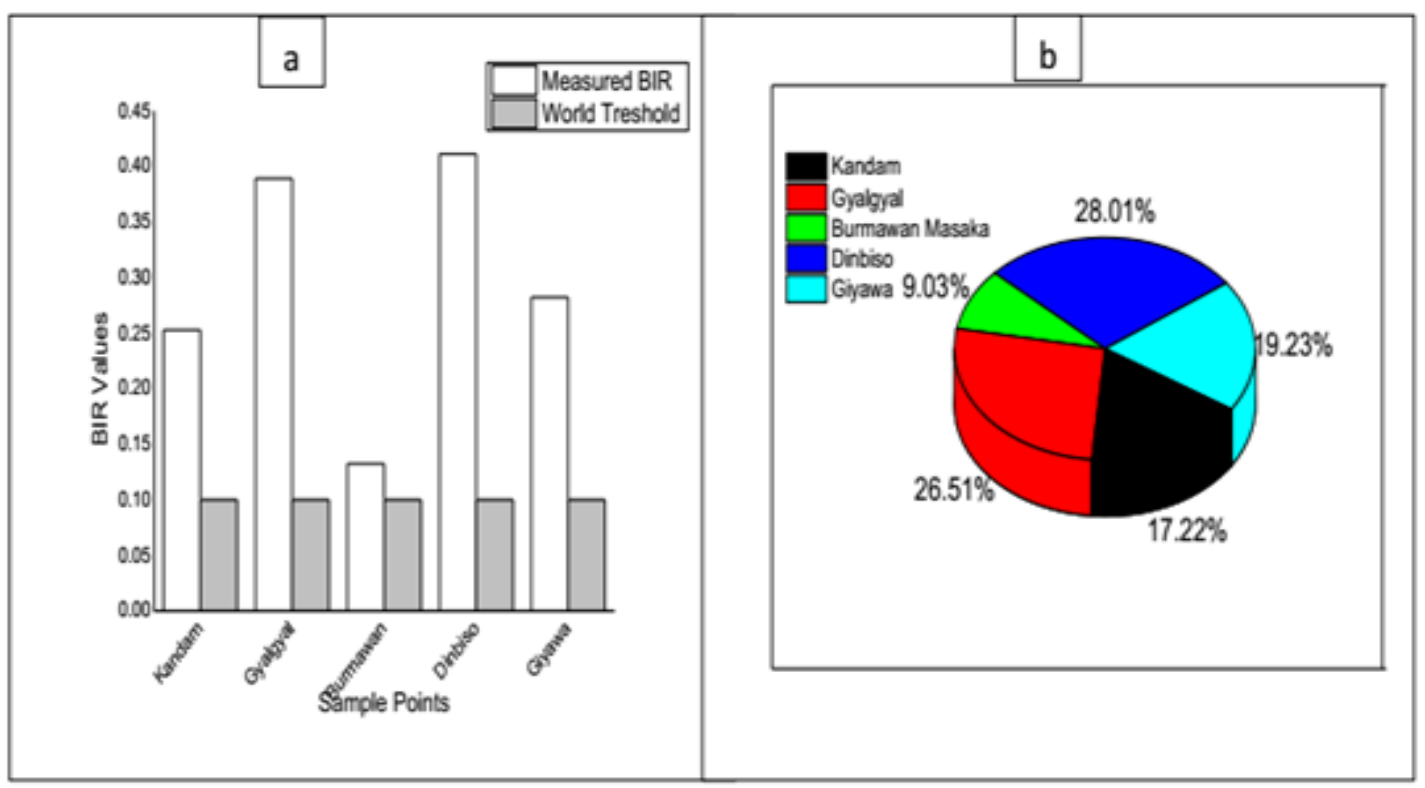

Fig.2(a,b). Illustrative charts of BIR Measured and calculated annual effective doses for sample points, Wurno LGA, Sokoto Nigeria

The life time cancer risk values were found in the range of $5.01 \times 10^{-1}$ and $1.56 \times 10^{1}$ which are all significantly higher than the world mean value of $3.44 \times 10^{-4}$ respectively according to Muneer et al. [19]. The results of the life time cancer risk indicate higher chances of cancers in a life time above global threshold. These results precede others that could be reported from Wurno and its environs and hence, more findings are suggested to dig deeper into this aspect. Also, the safety of the inhabitants of these localities is at stake if other anthropogenic factors are unabated as they could further lead to multiple and elevated impacts of radioactivity in the localities. In a similar trend, the results of the gross alpha/beta radioactivity from five sample points covered for Wurno LGA, Sokoto 
state are illustrated in figure 3 below. the data obtained from these results of five samples are plotted in form of scattered plots of figure 3. The values were in the range of 0.02 to $1.026 \mathrm{Bql}^{-1}$ and 2.082 to $8.087 \mathrm{Bql}^{-1}$ with mean values of 0.4466 and $4.9948 \mathrm{Bql}^{-1}$ for the gross alpha and beta activity respectively. The gross alpha and beta activity analysis from the water samples could be observed with significant variations owing to the facts that the differences in solubility of some lithological components, structures and mineralogical composition of particular place responsible factors for the variation. It could be observed that the level of alpha radioactivity is fairly lower than that of beta radioactivity in the water samples. This may account the higher concentrations of beta emitting radionuclides in these localities like ${ }^{40} \mathrm{~K}$ due to prominence of phosphate rocks in the basin. The mean values (0.4466 and $4.9948 B q l^{-1}$ for $\alpha$ and $\beta$ ) could be observed with significant elevation above the threshold of 0.1 $B q l^{-1}$ and $1.0 B q l^{-1}$ recommended by WHO [6]. The data revealed that the highest $\alpha$ activity was found in Kandam and Dinbiso respectively.

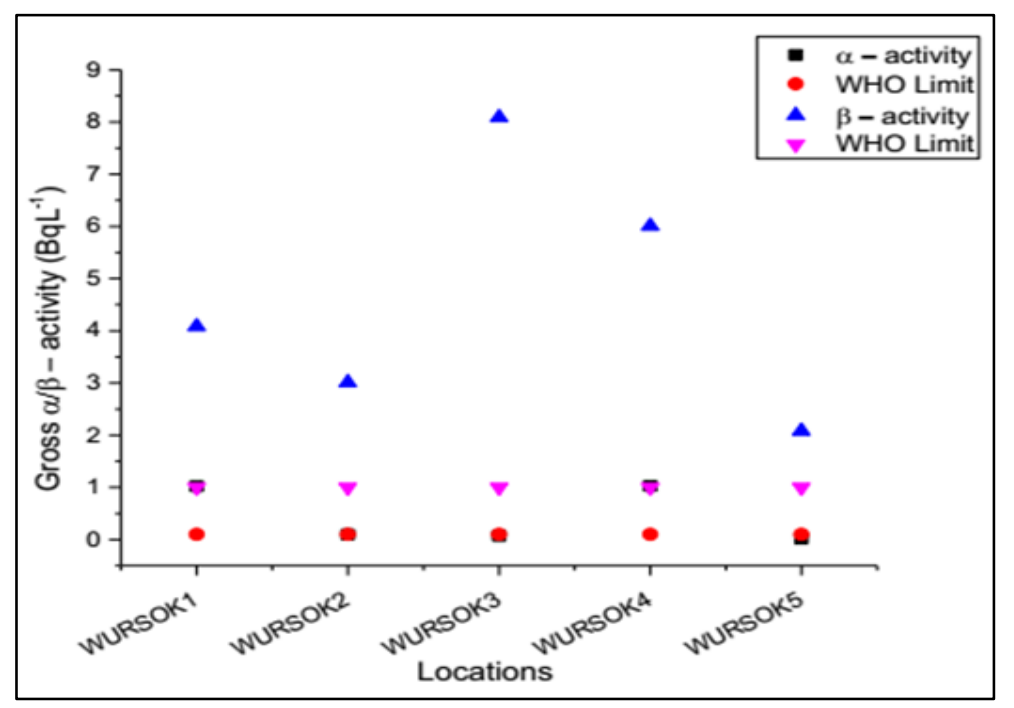

Fig.3. The gross alpha and beta activity in water samples from Wurno LGA

\begin{tabular}{|c|c|c|c|c|c|c|c|}
\hline \multirow{3}{*}{ Location } & \multicolumn{7}{|c|}{ Measured Gross Alpha and Beta Activity ( $\mathrm{Bql}^{-1}$ ) } \\
\hline & \multicolumn{3}{|c|}{ Gross Alpha } & \multicolumn{3}{|c|}{ Gross Beta } & \multirow[t]{2}{*}{ Source } \\
\hline & Min & Max & Mean & Min & Max & Mean & \\
\hline China & 0.009 & 0.20 & - & 0.067 & 0.32 & - & Miao et al., 2013 \\
\hline Turkey & 0.08 & 0.38 & 0.192 & 0.12 & 3.47 & 0.58 & Turhan et al. 2013 \\
\hline Malacca, Malaysia & 2.08 & 3.69 & - & 6.01 & 17.1 & - & Nik et al. 2011 \\
\hline Delta State & 0.006 & 0.02 & - & 0.046 & 0.13 & - & Ogundare \& Adekoya 2015 \\
\hline Abuja & 0.01 & 0.02 & - & 0.01 & 0.07 & - & Umar et al. 2012 \\
\hline Birnin Gwari & - & - & 18.13 & - & - & 102 & Muhammad et al., 2014 \\
\hline Dutsin-Ma, Katsina & & & 0.44 & & & 28.8 & Baba-Kutigi et al., 2016 \\
\hline Wurno, Sokoto St. & 0.02 & 1.03 & 0.45 & 2.08 & 8.07 & 5.00 & This study \\
\hline
\end{tabular}

While the highest $\beta$ activity concentrations were in Burmawan Masaka and also Dinbiso sample points. These trends may be due to the dispersed materials from the mining sites as a result of the primordial radionuclides unearthed from the mines. On the scale of comparison of the data in this article with other reported studies, table 3 shows the overview of radioactivity levels reported from drinking water that may be used for other domestic purposes. 


\section{Conclusions}

The mean annual effective dose to the public due to background ionizing radiation were found to be 0.252811 , 0.389035, 0.132542, 0.411125 and 0.282265 from Kandam, Gyalgyal, Burmawan Masaka, Dinbiso and Giyawa with the aid of Digilert-50 radiation measuring instrument. These are some of the major mining sites for Gypsum, Limestone, Phosphate, Kaolin etc. Comparison of this data with those of international committee for radiation protection has enabled us to determine that these values are significantly higher than the world recommended thresholds for BIR exposure.

Hence, the results obtained from this study stands as a baseline data for useful assessment on the radiation exposure level. Also, the gross alpha and beta radioactivity in the domestic water samples in the mining communities from Wurno LGA have been determined. While the level of radioactivity measured could pose no immediate danger but a risk of subsequent accumulation of individual dose exposure from internal irradiation. This study has established baseline data combining in-situ radioactivity measurement with gross alpha and beta activity concentrations in the mining communities of Wurno LGA of Sokoto state, Nigeria. This may be a reference assessment of possible radioactivity variations in the future.

\section{Acknowledgment}

The authors are thankful to the supports of Usmanu Danfodiyo University, Sokoto for the award of TET fund PhD bench work grant 2015/2016 to GCU, Lahore, Pakistan that enabled the success of this paper. Greater appreciations go to Staffs and members of Center for Advanced Studies in Physics, GCU, Lahore, Pakistan.

\footnotetext{
Declarations

Source of Funding

This research was supported by Usmanu Danfodiyo University, Sokoto with the award of TET fund PhD bench work grant 2015/2016.

\section{Competing Interests Statement}

The author declares no conflicts of interests relevant to this manuscript.

\section{Consent for publication}

Author declares that he/she consented for the publication of this research work.

\section{Availability of data and material}

The datasets analyzed in the current study are available within the manuscript.

\section{References}

[1] Ehsanpour, E., Abdi, M. R., Mostajaboddavati, M. and Hashem, B. 226Ra, 232Th and 40K contents in water samples in part of central deserts in Iran and their potential radiological risk to human population, Journal of Environmental Health Science \& Engineering, 12, pp.80-82, 2014.
} 
Mediterranean Journal of Basic and Applied Sciences (MJBAS)

Volume 5, Issue 3, Pages 18-28, July-September 2021

[2] Okosun, E. A., The potential application of Sokoto phosphate for the manufacture of fertilizer, Journal of Agricultural Technology, 2, 59-64, 1997.

[3] Ahijjo, Y. M., A Radiological Assessment of Mining Sites in the Sokoto basin. A Theses (Unpublished) submitted to the Post-Graduate School of Usmanu Danfodiyo University, Sokoto, Nigeria, 2019.

[4] Efu-Eteotor, J., A review of the mineral resources of Sokoto basin, Northwest Nigeria, Journal of Min. Geol., 34, 171-180, 1998.

[5] IAEA., Assessing the need for radiation protection measures in work involving minerals and raw materials, Safety reports series no. 49, IAEA, Vienna 2006.

[6] WHO, Over 90\% of world breathing bad Air-Health-Pulse. (Online), Available at: <http://pulse.ng/health/ world-health-organization-over-90-of-world-breathing-bad-airid5535389.html?utm_medium=email\&utm_campa ign=daily-2016-09-28\&utm_source=newsletter> [Accessed 29/09/2016].

[7] Yeboah, J., Boadu, M. and Darko, E. O., Natural radioactivity in soils and rocks within the greater Accra region of Ghana, J. Radiation. Nucl. Chem., 2001.

[8] Laurent, O., Ancelet, S., Richardson, D. B., Hemon, D., Ielsch, G. and Demoury, C., Potential impacts of radon, terrestrial gamma and cosmic rays on childhood leukemia in France: a quantitative risk assessment, Radiat Environ Biophys., 52, pp. 195-209, 2013.

[9] Khater, A. E., Higgy, R., Pimpl, M., Radiological impacts of natural radioactivity in Abu-Tartor phosphate deposits, Egypt, J. Environ. Radioact., 3, pp. 255-267, 2001.

[10] Bichi, T. S., Diso, D. G. and Abbati, A. M., Survey of level of radioactivity in drinking water at Wudil and its environs, Techno Science Africa Journal, Vol. 8, pp. 94-97, 2006.

[11] Jafaru A. M., Assessment of Sociological and Ecological Impacts of Sand and Gravel Mining - A Case Study of East Gonja District (Ghana) and Gunnarsholt (Iceland), Environmental Protection Agency Post Office Box 620 Tamale, Northern Region, Ghana Land Restoration Training Programme Final project 2009. Keldnaholt, 112 Reykjavík, Iceland, 75 pp, 2009.

[12] Zhilin, C., Shixiong, X., Heyi, W., ruimin, C., Guanyin, W and Yinhang, Z., The effect of vial type and cocktail quantity on tritium measurement in LSC, Elsevier Ltd., 2010.

[13] Singh, R. V. K. and Audu, A., Efficiency of Ratio Estimators in Stratified Random Sampling Using Information on Auxiliary Attribute, International Journal of Engineering Science and Innovative Technology, 2, pp. 166-172, 2013.

[14] Shamonda, J. A. and Maduabuchi, C. M., IAEA - Assisted Sahel Project RAF7011: Progress Report on the Iullemeden (Sokoto) Basin in Nigeria. Integrated and Sustainable Management of the Shared Aquifer System and Basins of the Sahel Region, Vienna, Austria, 5-8 May 2014.

[15] UNSCEAR, Source and Effects of Ionizing Radiation, UNSCEAR Report to the General Assembly, with scientific annexes, United Nations, New York, 1, pp. 17-61, 1993. 
[16] ICRP Age-depended doses to members of the public from intake of radionuclides: Part 5 Compilations of ingestion and Inhalation dose coefficient, ICRP Publications, 72, 1996.

[17] Nisti, M. B., Santos, A. J. G., Pires, M. A. F.., Contrim, M. E. B., Terezan, W. R., Method to Determine the Release Dilution Factor for Liquid Radioactive Effluent, Proceedings of the 2009 International Nuclear Atlantic Conference-INAC 2009, Rio de Janeiro, RJ, Brazil, Sept 27 - Oct 2, ISBN: 978-85-99141-03-8, 2009.

[18] UNSCEAR, (United Nations Scientific Committee on the Effects of Atomic Radiation), sources, Effects and risk of ionizing Radiation, 2000.

[19] Muneer, A. S., Ahmad, T. R., Yasser, A., Abubakar Sadiq, Y., Assessment of Natural Radiation Levels and Associated Dose Rates from Surface Soils in Pontian District, Johor, Malaysia, Journal of Ovonic Research, Vol. 9, No. 1, pp. 17- 27, 2013.

[20] Miao, X. -X., Ji, Y. -Q., Shao, X. -Z., Wang, H., Sun, Q. -F. and Su, X., Radioactivity of Drinking-Water in the Vicinity of Nuclear Power Plants in China Based on a Large-Scale Monitoring Study, International Journal of Environmental Research and Public Health, Vol. 10, pp. 6863-6872, 2013.

[21] Turhan, S., Ozc, stak, E., Taskın, H. and Varinlioglu, A., Determination of natural radioactivity by gross alpha and beta measurements in ground water samples, Elsevier, 47, pp. 3103- 3108, 2013.

[22] Nik, Azlin, N. A., Zal Uyun, W. M. and Che Abd Rahim, M., Application of in-House Method for Determination of Radium Isotopes in Environmental Samples Using the Liquid Scintillation Counting Technique, Journal of Analytical Sciences, Methods and Instrumentation, 20, pp. 1-8, 2011.

[23] Ogundare, F.O. and Adekoya, O. I., Gross alpha and beta radioactivity in surface soil and drinkable water around a steel processing facility, Journal of Radiation Research and Applied Sciences, 8, pp. 411- 417, 2015.

[24] Umar, A. M., Onimisi, M. Y. and Jonah, S. A., Baseline Measurement of Natural Radioactivity in Soil, Vegetation and Water in the Industrial District of the Federal Capital Territory (FCT) Abuja, Nigeria, British Journal of Applied Science \& Technology, 2, pp. 266-274, 2012.

[25] Muhammad, M. J., Jabirr, T. H. and Khalil, M. T., Transfer of Natural Radionuclides from Soil to Plants and Grass in the Western North of West Bank Environment-Palestine, International Journal of Environmental Monitoring and Analysis, 2, pp.252-258, 2014.

[26] Baba-Kutigi, A. N., Joseph, E., Tikyaa, E. V. and Sanni, D. M., Investigation of the Gross Alpha and Beta Activity Concentrations of Hand Dug Well Water from Dutsin-Ma Local Government, Katsina State-Nigeria, Journal of Natural Sciences Research, 6, pp. 64-70, 2016. 